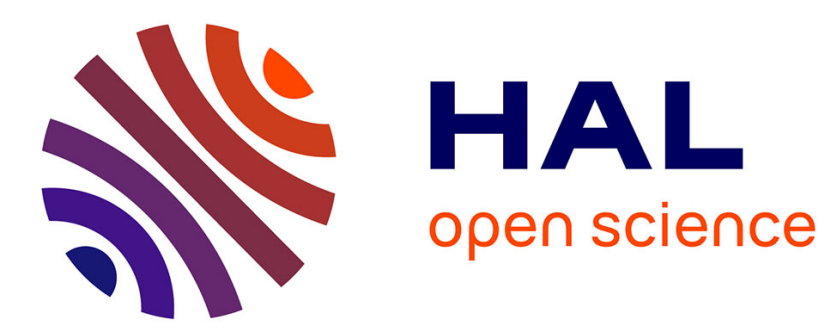

\title{
DETERMINATION OF BOUNDARY ENERGIES OF Cu FROM THE SHAPE OF BOUNDARY SiO2 PARTICLES
}

\author{
H. Miura, M. Kato, T. Mori
}

\section{- To cite this version:}

H. Miura, M. Kato, T. Mori. DETERMINATION OF BOUNDARY ENERGIES OF Cu FROM THE SHAPE OF BOUNDARY SiO2 PARTICLES. Journal de Physique Colloques, 1990, 51 (C1), pp.C1-263-C1-268. 10.1051/jphyscol:1990141 • jpa-00230299

\section{HAL Id: jpa-00230299 https://hal.science/jpa-00230299}

Submitted on 1 Jan 1990

HAL is a multi-disciplinary open access archive for the deposit and dissemination of scientific research documents, whether they are published or not. The documents may come from teaching and research institutions in France or abroad, or from public or private research centers.
L'archive ouverte pluridisciplinaire HAL, est destinée au dépôt et à la diffusion de documents scientifiques de niveau recherche, publiés ou non, émanant des établissements d'enseignement et de recherche français ou étrangers, des laboratoires publics ou privés. 


\title{
DETERMINATION OF BOUNDARY ENERGIES OF CU FROM THE SHAPE OF BOUNDARY SiO ${ }_{2}$ PARTICLES
}

\author{
H. MIURA, M. KATO and T. MORI \\ Department of Materials Science and Engineering, Tokyo Institute of \\ Technology, 4259 Nagatsuta, Midori-ku, Yokohama 227, Japan
}

\begin{abstract}
The boundary energies of symetric [011] tilt and [011] and [001] twist boundaries of $\mathrm{Cu}$ were measured by a new method: $\mathrm{SiO}_{2}$ particles were introduced on grain boundaries by internally oxidizing bicrystals of $\mathrm{Cu}-0.06 \% \mathrm{Si}$. The boundary energies in terms of the $\mathrm{Cu}-\mathrm{SiO}_{2}$ interfacial energy were determined from the lenticular shapes of boundary $\mathrm{SiO}_{2}$ particles observed by transmission electron microscopy. Besides the energy cusps reported previously for FCC metals, several new cusps were clearly resolved by the present method: $\Sigma 27,11,33$ and 57 for [011] twist and $\Sigma 41$ and 29 for [001] twist boundaries. The relative boundary energy was found to depend sensitively on the partial pressure of oxygen, as-oxidized or degassed. That is, oxygen segregates on boundaries, affecting the boundary energies.
\end{abstract}

\section{1 - INTRODUCTION}

It is generaliy accepted that the energies of grain boundaries play a central role in some phenomena associated with boundaries: fracture strength, boundary corrosion, boundary precipitation, the preference of particular boundaries in recrystallization and grain growth, etc/1-4/. Besides the work which attempted to examine-boundary energies in terms of arrays of dislocations/5/, many data of boundary energies have been accumulated so that other properties or phenomena involving boundaries can be discussed in correlation with the boundary energies. Most of the important data of the energies of well-characterized boundaries are documented in an overview by Sutton and Balluffi/6/.

Two methods have been traditionally employed to determine the energies of boundaries: surface groove and triple junction methods. These methods have some drawbacks in accurate measurements. It appears inhibitingly difficult to accurately measure the dihedral angle between two free surfaces in the surface groove method. This is particularly so at the very tip where a boundary emerges at a surface. There is also a case where a boundary consists of microscopically zig-zag facets which have lower energies than the boundary to be examined. An example of such a case will be given later. Although sufficient accuracy may be maintained in the measurement of dihedral angles in the triple junction method, this method also involves an uncertainty: the proper assignment of the so-called torque terms/7/ which are known only after the complete determination of the energies of boundaries with every possible orientations.

The present study employed a new technique in the determination of boundary energies in $\mathrm{Cu}$. Although the applicability of the technique was suggested earlier/8/, the technique has not been used in a systematic manner until now and, thus, will be described below. Introduce a $\mathrm{SiO}_{2}$ particle on a grain boundary of $\mathrm{Cu}$ by an adequate method. It is known that a $\mathrm{SiO}_{2}$ particle is spherical inside a $\mathrm{Cu}$ grain after sufficient time of annealing at high temperatures/8/. Such in-grain spherical particles are seen in Fig. 1. This means that the interfacial energy between $\mathrm{Cu}$ and $\mathrm{SiO}_{2}$ does not depend on the orientation of a $\mathrm{Cu}-\mathrm{SiO}_{2}$ interface and is isotropic. Under this condition, it can be shown that a $\mathrm{SiO}_{2}$ particle on a boundary takes a lenticular shape bounded by two truncated spherical surfaces, as shown by the inset in Fig. 1, after the equilibrium (energy minimum) is attained. The boundary plane forms 


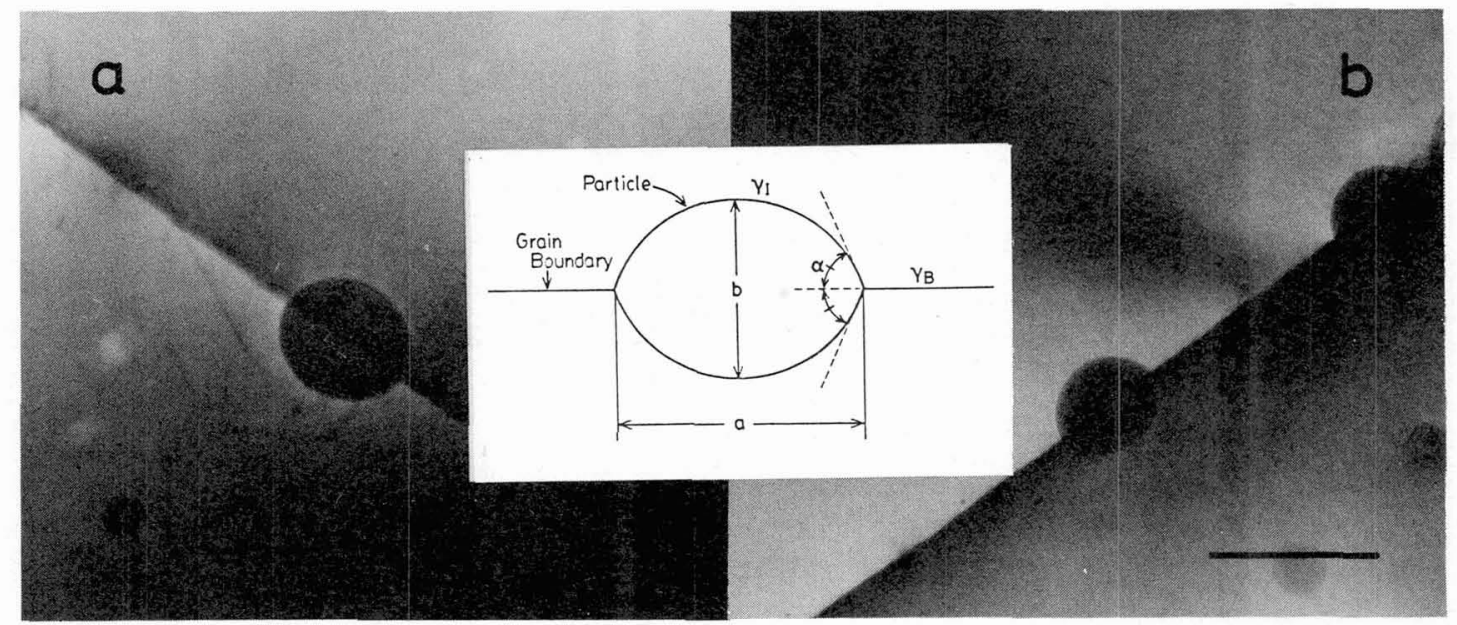

Fig. 1, $-\mathrm{SiO}_{2}$ particles on (a) $\Sigma 11\{311\}\{311\}$ and (b) $\sum 9\{122\}\{122\}$ boundaries. The scale bars are $0.5 \mu \mathrm{m}$. In-grain particles are also seen.

the mirror plane of symmetry. $\alpha$, half the dihedral angle of the equilibrium lenticular shape, is given by

$$
\gamma_{B} / \gamma_{I}=2 \cos \alpha,
$$

where $\gamma_{B}$ is the energy of the boundary between two abutting grains and $\gamma_{I}$ the interfacial energy between $\mathrm{Cu}$ and $\mathrm{SiO}_{2}$. Thus, by measuring $\alpha$ of the lenticular shape of a boundary $\mathrm{SiO}_{2}$ particle, we can determine the relative boundary energy, $\gamma_{B} / \gamma_{I}$. The direct application of Eq. (1) requires the determination of $\alpha$, the measurement which may involve a certain degree of inaccuracy. However, this apparent drawback can be overcome: simple geometrical consideration leads to $\cos \alpha=\left(a^{2}-b^{2}\right) /\left(a^{2}+b^{2}\right)$, where a is the diameter of the SiO 2 particle on the boundary and $b$ the distance between the two apexes of the lenticular shaped particle, as shown in Fig. 1. Thus, Eq. (1) is rewritten as

$$
\gamma_{B} / \gamma_{I}=2\left(a^{2}-b^{2}\right) /\left(a^{2}+b^{2}\right) \text {. }
$$

It is obvious that the measurement of a and b involves less uncertainty. The actual determination of the shape of boundary $\mathrm{SiO}_{2}$ particles was made after the spherical shape of in-grain $\mathrm{SiO}_{2}$ was confirmed. This was to ensure that sufficient time had been allowed for diffusion of $\mathrm{Cu}$ and the constituents of $\mathrm{SiO}_{2}$ to attain the equilibrium.

The isotropy of the interfacial energy of $\mathrm{Cu}-\mathrm{SiO}_{2}$ eliminates an unknown role of the torque terms in the calculation of boundary energies. Besides this advantage, the present method is free of ambiguity that occurs in a boundary which might consist of facets but looks macroscopically flat. By the present method, we can always ascertain that the boundary whose energy is measured is straight in a microscopic scale. An example of a boundary with facets will be given later.

In the present study, we have measured the energies of symmetric [011] tilt and [011] and [001] twist boundaries in $\mathrm{Cu}$, using the above mentioned method. We have also found that the presence of small amounts of an impurity (oxygen) in the bulk changes the energy of a boundary.

\section{2 - EXPERIMENTAL}

Bicrystals, $2 \mathrm{~mm}$ thick, of Cu-0.06\%Si having symmetric [011] tilt, [011] twist and [001] twist voundaries were grown by the Bridgman method in graphite molds, using seeds. After annealing at $1273 \mathrm{~K}$, the bicrystals were internal1y oxidized at $1273 \mathrm{~K}$ for $24 \mathrm{hr}$ by the pack method with a mixture of $\mathrm{Cu}, \mathrm{Cu}_{2} \mathrm{O}$ and $\mathrm{Al}_{2} \mathrm{O}_{3}$ powders. They were further degassed at $1273 \mathrm{~K}$ for $24 \mathrm{hr}$ in vacuum on a graphite mold for standard measurements. The effect of degassing will be mentioned later. The shape of $\mathrm{SiO}_{2}$ particles formed by these treatments was examined by transmission electron microscopy $(200 \mathrm{kV})$. Thin foils, containing grain boundaries, for this observation were prepared by mechanical polishing and jet polishing in an electrolyte of $\mathrm{H}_{2} \mathrm{O}$ and $\mathrm{H}_{3} \mathrm{PO}_{4}$. For each boundary, more than fifteen particles were observed in the orientation where the grain boundary was always parallel to the incident electron beam. The relative 


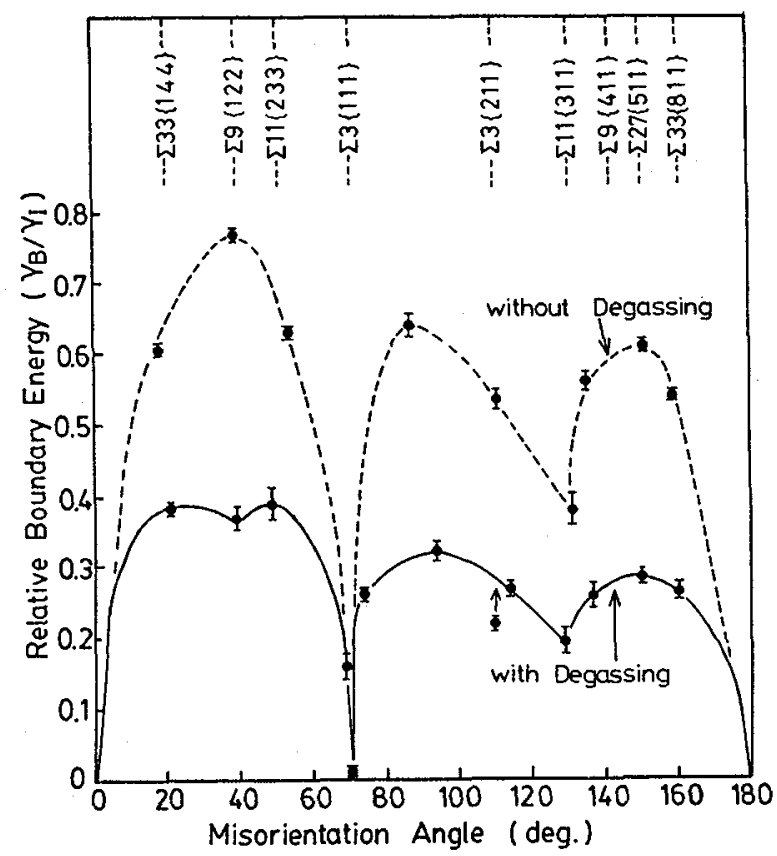

Fig. 2 - Relative boundary energy against misorientation angle for symmetric [011] tilt boundaries of $\mathrm{Cu}$. Relative boundary energy is higher after oxidation (the dotted curve) than that with an additional degassing treatment (the solid curve).

boundary energies were calculated from the observed shapes of $\mathrm{SiO}_{2}$ particles with Eq. (2). In some cases, $\mathrm{SiO}_{2}$ particles on a boundary were observed from two directions, approximately $90^{\circ}$ from each other, to ensure that the particles had mirror symmetry lenticular shapes. A change in the calculated energy in this assertion was within the standard deviation for the energy of an individual boundary.

\section{3 - RESULTS AND DISCUSSION}

\subsection{Boundary energy}

Examples of $\mathrm{SiO}_{2}$ particles on symmetric [011] tilt boundaries are shown in Figs. 1(a) and (b). Figure 1(a) was taken from a $\sum 11\{311\}\{311\}$ boundary and Fig. 1(b) from a $\sum 9\{122\}\{122\}$ boundary. The spherical shape of in-grain particles ensures that the equilibrium has been attained in a practical sense. The $\mathrm{SiO}_{2}$ particles on the $\Sigma 9$ boundary in Fig. I(b) are more oblate than that on the $\Sigma 11$ boundary in Fig. 1(a). That is, just visually examining the shape of $\mathrm{SiO}_{2}$ particles, we can roughly judge the magnitude of the energy of a boundary: the energy of the $\Sigma 9\{122\}\{122\}$ boundary is larger than that of the $\Sigma 11\{311\}\{311\}$ boundary.

Figure 2 is the $\gamma(\theta)$ diagram where the energies $\gamma B$ of symmetric [011] tilt boundaries are plotted against the misorientation angle $\theta$. The solid curve was obtained from oxidized and degassed bicrystals and the dotted curve from as-oxidized bicrystals without the degassing treatment. The effect of the degassing treatment on boundary energies will be discussed later. The general shape of the solid curve is similar to those observed for A1 by Hasson and Goux/9/ and Otsuki and Mizuno/10/. Similar to Hasson and Goux, we were able to resolve the cusp at $\theta=39^{\circ}, \sum 9\{122\}\{122\}$, in addition to the well established cusps at $\theta=70.5^{\circ}, \Sigma 3$ $\{111\}\{111\}$, and $\theta=130^{\circ}, \Sigma 11\{311\}\{311\}$. Its existence is backed by the smal1 scatter of data in the present study. The implication by Sutton and Balluffi[6] that a cusp exists at $\theta=110^{\circ}$, $\Sigma 3\{211\}\{211\}$ has not been definitely confirmed. The data point for this value is the lower bound as will be described below, but it cannot indicate the presence of a cusp without reservation.

We attempted to grow several times bicrystals with the $\sum 3\{211\}\{211\}$ boundaries. However, it was found that the boundaries, macroscopical1y described by $\{211\}\{211\}$, always consisted of two flat facets, one inclining by $6.7^{\circ}$ to $\{211\}$ and the other by $-6.7^{\circ}$ to $\{211\}$. This observation does not coincide with the existence of the energy cusp at $\{211\}\{211\}$ for [011] tilt $\sum 3$ boundaries as reported by Goodhew, Tan and Balluffi and Andreyeva and 


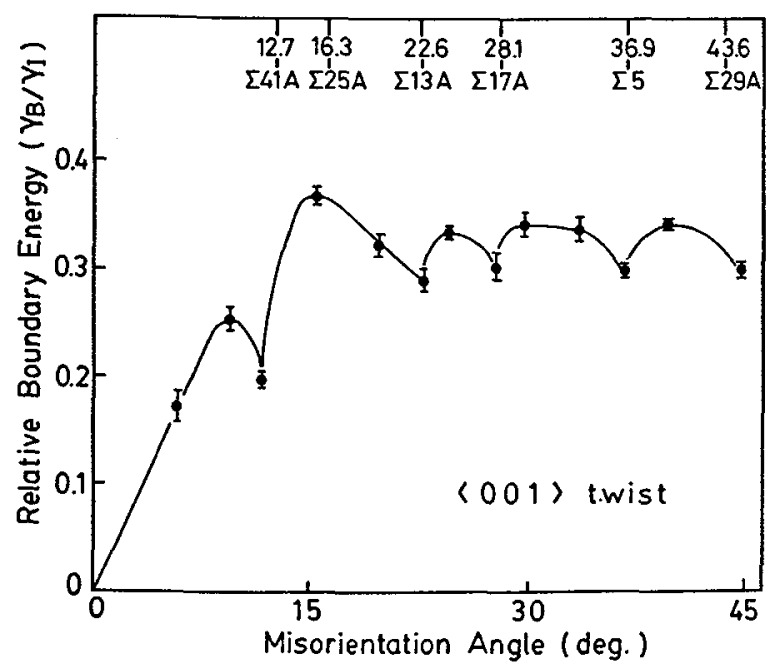

Fig. 3 - Relative boundary energy against misorientation angle for [001] twist boundaries.

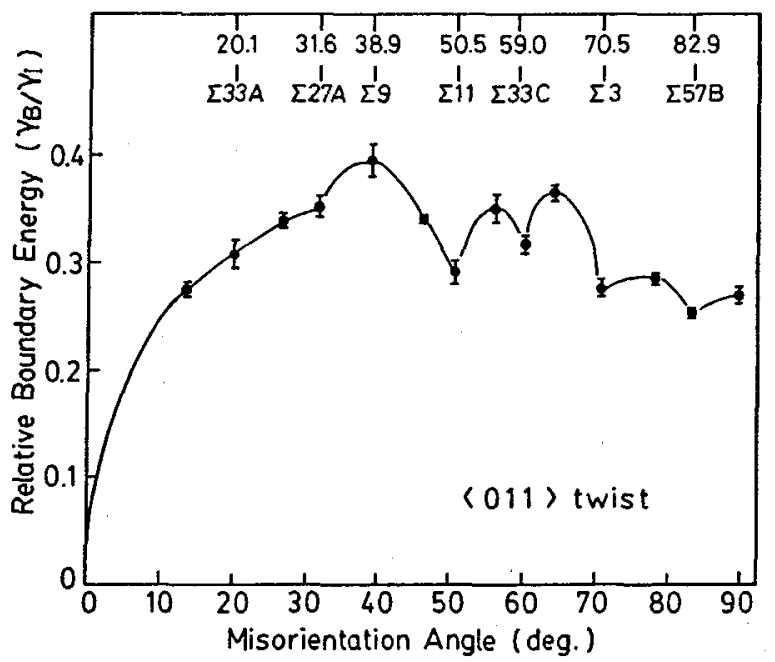

Fig. 4 - Relative boundary energy against misorientation angle for [011] twist boundaries.

Fionova/11,12/. These facet planes were tentatively assigned to $\left\{\begin{array}{lllllll}13 & 5 & 5\end{array}\right.$. 7 . 7 by referring to Vaughan/13/, who found similar boundaries in an annealed polycrystalline austenitic stainless steel. The present finding of the faceting of $\{211\}\{211\}$ to $\{1355\}\{1177\}$ and the observation by Vaughan indicate that the $\left\{\begin{array}{lll}13 & 5\end{array}\right\}\{1177\}$ boundary has a lower energy than the symmetric $\{211\}\{211\}$ boundary. By examining the shape of $\mathrm{SiO}_{2}$ particles, the relative boundary energy of $\left\{\begin{array}{lll}13 & 5 & 5\end{array}\right\}\left\{\begin{array}{lll}11 & 7 & 7\end{array}\right\}$ was determined to be 0.22 . From this, the lower bound for the relative energy of $\sum 3\{211\}\{211\}$ was calculated as slightly larger than 0.22 . This discussion indicates an advantage in the present method of the boundary energy determination.

Figure 3 is the $\gamma(\theta)$ curve for the [001] twist boundaries. The existence of the energy cusps at $\theta=23^{\circ}(\Sigma 13), \theta=28^{\circ}(\Sigma 17)$ and $\theta=37^{\circ}(\Sigma 5)$, as observed in Al by Otsuki and Mizuno/10/, was confirmed. In addition, two more cusps at $\theta=13^{\circ}$ ( $\Sigma 41$ ) and possibly at $\theta=44^{\circ}(\Sigma 29)$ were found. Brokman and Balluffi expected by simulation calculations that the $\theta=16.3^{\circ}$ ( $\Sigma 25$ ) boundary is associated with an energy cusp/14/. However, Figure 3 clearly denies such an expectation but rather indicates that the [001] twist $\Sigma 25$ boundary with the fourth lowest $\Sigma$ value has an energy close to that of a random boundary. In accordance with this observation, we recently found that the sliding behavior of a [001] twist $\Sigma 25$ boundary deviates from those of other low $\Sigma$ boundaries and is close to that of a random boundary. 


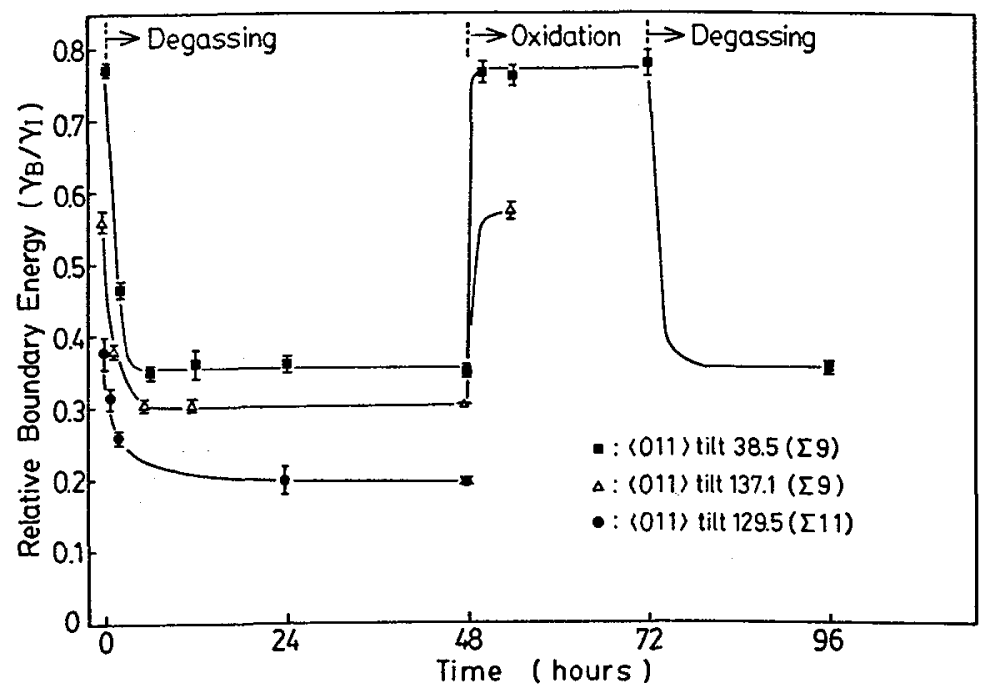

Fig. 5 - The effect of degassing and re-oxidation on relative boundary energies.

Figure 4 shows the energy of [011] twist boundaries against the misorientation angle. In the past, only a shallow cusp at $\theta=70.5^{\circ}(\Sigma 3)$ was reported for $A 1 / 10 /$. The cusp at $\theta=70.5^{\circ}$ observed in the present study is highly asymmetric but is sharp. In addition to this, we have

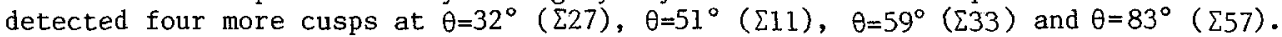

We will briefly discuss why we have found new cusps. Certainly, the energy is determined not only by the character of a boundary but also by a material property. The fact that most of the energy cusps found in the present study of $\mathrm{Cu}$ for the [011] tilt and [001] twist boundaries were also observed in Al suggests that the former effect is predominantly operative. It appears that the discovery of new cusps at $\Sigma 29$ and $\Sigma 41$ in [001] twist boundaries and those at $\Sigma 27, \Sigma 11, \Sigma 33$ and $\Sigma 57$ in [011] twist boundaries is due to better sensitivity in the present method.

\subsection{Effect of degassing and re-oxidation - Reproducibility of boundary energy}

$\mathrm{SiO}_{2}$ particles were formed by the pack method which produced an oxygen partial pressure of $\sim 10^{-2} \mathrm{~Pa}$ (dissociation pressure of $\mathrm{Cu}_{2} \mathrm{O}$ ). When $\mathrm{SiO}_{2}$ particles were observed and the corresponding boundary energies were determined without a degassing treatment, we obtained the dotted curve in Fig. 2 for [011] tilt boundaries. It is clear that the relative boundary energies depend on the oxygen pressure under which the equilibrium state is attained. Two factors must be considered to discuss this observation. Both of them are caused by the segregation of oxygen; one on grain boundaries and the other on $\mathrm{Cu}-\mathrm{SiO}_{2}$ interfaces. It is obvious that the segregation on boundaries or interfaces changes their energies. As shown in Fig. 2, the relative energy is higher in the as-oxidized condition than in the degassed condition. This means that either the interfacial energy of $\mathrm{Cu}-\mathrm{SiO}_{2}$ becomes smaller or the boundary energy of $\mathrm{Cu}$ increases by the oxygen segregation. The equilibrium oxygen segregation on the $\mathrm{Cu}-\mathrm{SiO}_{2}$ interface is determined solely by the oxygen partial pressure. Thus, if only the interfacial energy of $\mathrm{Cu}-\mathrm{SiO}_{2}$ is affected by the magnitude of the oxygen pressure, the two curves in Fig. 2 should become identical except for a multiplication factor. However, this is not necessarily the case. The clearest evidence against the supposition that only the $\mathrm{Cu}-\mathrm{SiO}_{2}$ interface has the segregation of oxygen is the feature of the energies around $\theta=39^{\circ}(\Sigma 9)$. In the degassed state, the $\theta=39^{\circ}$ boundary has an energy cusp while in the as-oxidized state, the existence of a cusp is obscured. In short, it is our contention that the segregation of oxygen occurs in $\mathrm{Cu}$ grain boundaries and increases their energies. It is very likely that the amount of oxygen segregation on a grain boundary and the corresponding increase in its energy depend on the character of the boundary.

Next, we will show that the relative boundary energies given in Figs. 2 to 4 can be taken as the equilibrium values in their respective conditions, degassed or oxidized, for all practial purposes. We will further show that these values are reproduced reversibly in the degassing or oxidizing condition when sufficient time is allowed for the achievement of equilibrium by diffusion.

In Fig. 5, the relative boundary energies, determined by the shape of $\mathrm{SiO}_{2}$ particles, are 
plotted against degassing or oxidation time at $1273 \mathrm{~K}$ for three symmetric [011] tilt boundaries; $\theta=39^{\circ}, 130^{\circ}$ and $137^{\circ}$. The foils for this observation were taken from the center of $2 \mathrm{~mm}$ thick samples. As seen here, the relative boundary energies decrease rapid1y in the early stage of degassing and later saturated to almost constant values after $24 \mathrm{hr}$ degassing. This observation assures that the $24 \mathrm{hr}$ degassing employed in the standard measurement of boundary energies is sufficiently long. After $48 \mathrm{hr}$ degassing, $2 \mathrm{~mm}$ thick samples were again oxidized at $1273 \mathrm{~K}$ by the pack method and the relative boundary energies were measured using foils taken from the center of the samples. It is seen that the relative boundary energies increase rapidly to approach the values determined in the as-oxidized state. These observations indicate that the present method to determine the boundary energies is sufficiently sensitive to reflect the state of boundaries. Figure 5 also shows that the second degassing decreases the energies to the value obtained by the first degassing.

Whichever dominantly affects the relative boundary. energy, the segregation of oxygen on a $\mathrm{Cu}$ boundary or a $\mathrm{Cu}-\mathrm{SiO}_{2}$ interface, the above observations show that a change in the boundary or interfacial energy by the oxygen segregation can be detected reproducibly. Although the elimination of oxygen segregation cannot be completely claimed in the present degassing treatment, the energy determined after degassing should be closer to the intrinsic value.

Utilizing this change of the shape of $\mathrm{SiO}_{2}$ particles on boundaries by degassing or reoxidation, we can possibly estimate the diffusivity of oxygen along grain boundaries. We can also examine the dependence of oxygen diffusivity on the character of boundaries. These subjects will be reported in a separate paper.

\section{4 - SUMMARY}

After introducing $\mathrm{SiO}_{2}$ particles on boundaries of bicrystals of $\mathrm{Cu}$ by internally oxidizing $\mathrm{Cu}-\mathrm{Si}$, the shapes of the particles were observed by transmission electron microscopy. From the shape of the particles, the boundary energy relative to that of the $\mathrm{Cu}-$ $\mathrm{SiO}_{2}$ interface was determined. The results obtained were as follows:

(1) Symmetric [011] tilt boundaries have energy minima at $\theta=39^{\circ}(\Sigma 9), \theta=70.5(\Sigma 3)$ and $\theta=130^{\circ}$

( $\Sigma 11)$ ( $\theta$ is the misorientation angle), as reported previously in other FCC metals.

(2) Besides $\theta=70.5^{\circ}(\Sigma 3)$, the $\theta=32^{\circ}(\Sigma 27), \theta=51^{\circ}(\Sigma 11), \theta=59^{\circ}$ ( $\left.\Sigma 33\right)$ and $\theta=83^{\circ}(\Sigma 57)[011]$ twist boundaries have energy minima.

(3) New energy cusps were found at $\theta=13^{\circ}(\Sigma 41)$ and $\theta=43^{\circ}$ ( $\left.\Sigma 29\right)$ in [001] twist boundaries.

(4) Degassing treatments reduced the relative boundary energies from the as-oxidized state. Re-oxidation treatments increased the energies back to those in the as-oxidized state. This finding means that oxygen segregates on boundaries and affects boundary energies.

Acknowledgement

This research was part1y supported by a Grant-in-Aid for Scientific Research from the Ministry of Education, Science and Culture (No. 63550533).

\section{REFERENCES}

/1/ Sato, K., Miyazaki, H., Ikuhara, Y., Kurishita H. and Yoshinaga, H., J. Japan Inst. Metals 53 (1989) 536.

/2/ Yamashita, M., Mimaki, T., Hashimoto, S. and Miura, S., Scripta metal1. 22 (1988) 1087.

/3/ Czurratis, P., Kroggel, R. and Löfer, H., Z. Metallk. 79 (1988) 307.

14/ Watanabe, T., Fujii, H., Oikawa, H. and Arai, K.I., Acta meta11. 37 (1989) 941.

/5/ Gjostein, N.A. and Rhines, F.N., Acta metall. 5 (1959) 319.

/6/ Sutton, A.P. and Balluffi, R.W., Acta metall. $\overline{35}$ (1987) 2177.

$/ 7 /$ Herring, C., Physics of Powder Metallurgy, McGraw-Hill, 1951.

/8/ Ashby, M.F. and Smith, G.C., J. Inst. Metals 91 (1963) 182.

/9/ Hasson, G.C. and Goux, C., Scripta metal1. 5 (1971) 889.

/10/ Otsuki, A. and Mizuno, M., Grain Boundary Structure and Related Phenomona, Proc. JIMIS-4, (1986) 789 .

/11/ Goodhew, P.J., Tan, T.Y. and Balluffi, R.W., Acta meta11. 26 (1978) 557.

$112 /$ Andreyeva, A.V. and Fionova, L.K., Phys. Metals Meta11. 32 (1981) 122.

/13/ Vaughan, D., Phil. Mag. 22 (1970) 1003.

/14/ Brokman, A. and Balluffi, R.W., Acta metall. 29 (1981) 1703. 